\title{
OPTIMIZATION OF CONFORMAL CARTOGRAPHIC PROJECTIONS FOR THE SLOVAK REPUBLIC ACCORDING TO CHEBYSHEV'S THEOREM
}

\author{
Daniel SZATMÁRI ${ }^{*}$
}

\section{Abstract}

Disadvantages of the currently used Křvák's map projection in the Slovak Republic, such as large scale distortion, became evident after the division of Czechoslovakia. The aim of this paper is to show the results of the optimization of cartographic projections using Chebyshev's theorem for conformal projections and its application to the territory of the Slovak Republic. The calculus used, the scale distortions achieved and their comparison with the scale distortions of currently used map projections will be demonstrated.
Address

1 Department of Mathematics and Descriptive Geometry, Faculty of Civil Engineering, Slovak University of Technology, Radlinského 11, Bratislava 810 05, Slovakia

* Corresponding author: daniel.szatmari@stuba.sk

\section{Key words}

- Conformal cartographic projection, extremal criteria, minimax criteria, scale distortion.

\section{INTRODUCTION}

One of the basic problems in cartography is the problem of optimal map projections, especially for large-scale maps. The currently used cartographic projection in the Slovak Republic is Křovák's projection, which was designed in 1922 solely for Czechoslovakia. It is an oblique case of a conformal conic projection based on two preserved parallels. Bessel's reference ellipsoid is transformed into a sphere (using Gauss' conformal projection), which is transformed to a secant cone in an oblique position. The coordinates are positive in the south and west (Srnka, 1986). The disadvantages of this projection, such as large scale distortion, became evident after the division of Czechoslovakia, and the problem of optimal cartographic projections became quite real. In 2010, a new projection was designed at the request of the Geodesy, Cartography and Cadastre Authority of the Slovak Republic, i.e., a conformal conic Lambert's projection in a normal position with parameters for Slovakia (Vajsáblová, 2011). The GRS 1980 reference ellipsoid is transformed directly to a secant cone in a normal position. The coordinates are positive in the north and east. The aim of this article is to demonstrate the results of the optimization of the conformal map projections using extremal and minimax criteria for the Slovak Republic. Examples of the use of these criteria to derive and optimize map projections for other territories (Canada, the Czech Republic) and their valuation are described in (Frankich, 1982) and (Hojovec et al., 1997; Skořepa and Dušek, 1997).

\section{CARTOGRAPHIC PROJECTIONS AND THEIR VALUATION}

\subsection{Cartographic projections and distortions}

Cartographic projections can be defined as a mathematical transformation of a three-dimensional surface of a sphere (defined by its radius $R$ ) or an ellipsoid (defined by its semimajor axis $a$ and semiminor axis $b$ or eccentricity $e$ ) onto a plane. A point on the surface of an ellipsoid is referenced by its latitude $\varphi$ and longitude $\lambda$. The mathematical transformation between its ellipsoidical coordinates $\varphi, \lambda$ and planar coordinates $x, y$ is given by a projection formula:

$$
x=f(\varphi, \lambda) \quad y=g(\varphi, \lambda) .
$$


A point on the surface of a sphere is referenced by its latitude $U$ and longitude $V$ and the formulas of the projection in general:

$$
x=f(U, V) \quad y=g(U, V) .
$$

Representing a three-dimensional surface causes distortion in its shape, area and distance. The scale distortion of a projection is characterized by the scale distortion factor. The scale distortion factor is defined as the ratio of a differentially small distance on a mapping plane $\mathrm{d} S$ and the corresponding differential element on the reference surface ds:

$$
m=\frac{\mathrm{d} S}{\mathrm{~d} s} .
$$

The angular distortion of a projection is characterized by:

$$
\Delta \omega=\omega^{\prime}-\omega,
$$

where $\omega^{\prime}$ is an angle measured on the mapping plane, and $\omega$ is the corresponding angle on the reference surface.

The distortion of the area of a projection is characterized by the area distortion factor:

$$
m_{\text {area }}=\frac{\mathrm{d} P}{\mathrm{~d} p}
$$

where $\mathrm{d} P$ is the differential element of the surface on the mapping plane, and $\mathrm{d} p$ is the corresponding differential element of the surface on the reference surface.

Different projections cause different types of distortions:

(i) conformal projections - preserve angles,

(ii) equal area projections - preserve the areas,

(iii) equidistant projections - preserve selected distances.

Conformal projections are the most frequently applied map projections in geodetic coordinate systems.

\subsection{Design of a cartographic projection} tions:

The design of the most suitable map projection involves two op-

(i) we choose the group of projections according to the purpose of the future map and calculate the parameters of the projection according to the distortion requirements (requirement of one standard parallel, requirement of two standard parallels, etc.) - this option is decribed in (e.g. Vajsáblová, 2014) for the territory of the Slovak Republic,

(ii) we calculate the parameters of the ideal projection without any restrictions using the criteria described in the following sections; these map projections are only defined in terms of mathematical formulae and have no direct geometric interpretation.

\subsection{Valuation of cartographic projections}

Cartographic projections can be valuated using the following criteria (Hojovec and Šmehil, 1968):

a) extremal and minimax criteria - we evaluate conformal projections by:

- maximal value of the scale distortion: $|m-\mathbf{1}|_{\text {max }}$

- maximal value of the area distortion: $\left|m_{\text {area }}-\mathbf{1}\right|_{\max }$,

- quotient of the extremal values of the scale distortion factors: $m_{\max } / m_{\min }$.
Equidistant projections and equal area projections can be valuated by the maximal value of the angular distortion $|\Delta \omega|_{\text {max }}$.

According to Chebyshev's theorem for conformal projection, the natural logarithm of scale distortion is the least different from zero, if the scale distortion of the closed boundary curve is constant (Chebyshev, 1962). Projections derived using these criteria are called minimax type projections.

b) variational (additive, integral) criteria - the most popularized variational criterion for the valuation of map projections are:

i. Airy's criterion (Airy, 1861), where $h^{2}$ is the mean quadratic scale distortion defined by the extremal factors of the scale distortions $m_{a}, m_{b}$ :

$$
h^{2}=\frac{1}{2}\left[\left(m_{a}-1\right)^{2}+\left(m_{b}-1\right)^{2}\right],
$$

for conformal projections $m_{a}=m_{b}=m$ :

$$
h^{2}=(m-1)^{2} \text {. }
$$

ii. Airy-Kavraiskii's criterion (Kavraiskii, 1959), which is the modification of the previous equation using the logarithmic values:

$$
h^{2}=\frac{1}{2}\left(\ln ^{2} m_{a}+\ln ^{2} m_{b}\right),
$$

for conformal projections $m_{a}=m_{b}=m$ :

$$
h^{2}=\ln ^{2} m
$$

The characteristic value of the cartographic projection of the domain $\Delta$ of the reference surface is:

$$
I=\frac{1}{\Delta} \int_{V_{1}}^{V_{2}} \int_{U_{1}}^{U_{2}} h^{2} \cos U \mathrm{~d} U \mathrm{~d} V .
$$

The characteristic value of the cartographic projection for the $N$ chosen points is:

$$
I=\frac{1}{N} \sum_{i=1}^{N} h_{i}^{2}
$$

The mentioned criteria are possible to use in deriving cartographic projections too; we can thereby obtain a variational type of projection.

\section{OPTIMIZATION OF A CONFORMAL CARTOGRAPHIC PROJECTION USING CHEBYSHEV'S THEOREM}

The first step used to derive a minimax cartographic projection is to apply Chebyshev's theorem for the extremal criterion for a conformal projection; we need to minimize the natural logarithm of the scale distortion of the closed boundary points:

$$
\sum_{i=1}^{N} \ln ^{2} m_{i}=\min
$$

In conformal projections it holds (Urmaev, 1947):

$$
\frac{\partial^{2} \ln v}{\partial Q^{2}}+\frac{\partial^{2} \ln v}{\partial V^{2}}=0,
$$

where $Q$ is an isometric latitude calculated by: 


$$
Q=\ln \tan \left(\frac{U}{2}+45^{\circ}\right)
$$

and

$$
v=m \cos U .
$$

The solution of (13) has the shape:

$$
\ln v=\sum_{j=0}^{n}\left(a_{j} \psi_{j}+b_{j} \tau_{j}\right)
$$

where $\psi_{j}$ and $\tau_{j}$ are determined by:

$$
\psi_{j}+i \tau_{j}=(Q+i V)^{j}
$$

After the separation of the real and imaginary components of the complex variables:

$$
\begin{aligned}
& \psi_{0}=1, \\
& \psi_{1}=Q, \\
& \psi_{2}=Q^{2}-V^{2}, \\
& \psi_{3}=Q^{3}-3 Q V^{2}, \\
& \psi_{4}=Q^{4}-6 Q^{2} V^{2}+V^{4} \\
& \tau_{0}=0, \\
& \tau_{1}=V, \\
& \tau_{2}=2 Q V, \\
& \tau_{3}=3 Q^{2} V-V^{3}, \\
& \tau_{4}=4 Q^{3} V-4 Q V^{3} .
\end{aligned}
$$

The aim of this article is to show the results of the optimization of conformal map projections using Chebyshev's theorem for the territory of the Slovak Republic and to compare the scale distortions achieved by the proposed projections, depending on the choice of boundary points. These points can be defined as a spherical trapezium delimiting the country's territory in a normal or oblique position, or we can define them as the country's actual boundary points (Fig. 1).

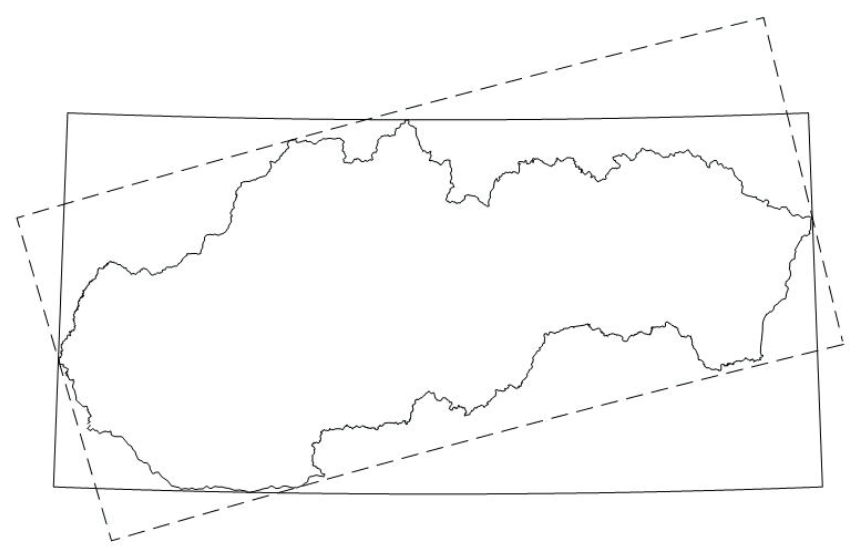

Fig. 1 Spherical trapeziums delimiting the country's territory - parts of the geographic parallels and meridians in a normal position (solid line) or parts of the cartographic parallels and meridians in an oblique position (dashed line).

\subsection{Minimax projection in a normal position (geographic trapezium)}

The first minimax cartographic projection is designed for a geographic trapezium delimiting the territory of the Slovak Republic. The geographic coordinates $\varphi, \lambda$ of the boundary points on the reference ellipsoid GRS 1980 have been transformed on the spherical coordinates $U, V$ by Gauss' conformal projection:

$$
\tan \left(\frac{U}{2}+45^{\circ}\right)=k\left[\tan \left(\frac{\varphi}{2}+45^{\circ}\right) \sqrt{\left(\frac{1-e \sin \varphi}{1+e \sin \varphi}\right)^{e}}\right]^{\alpha}, V=\alpha \lambda
$$

with the parameters: $\alpha=1.000640596751$ and $k=1.003315995637$. The radius of the sphere is $R=6380840.7213 \mathrm{~m}$. The Slovak Republic is situated on this sphere between parallels with the geographic latitudes $U_{S}=47^{\circ} 41^{\prime} 27.0720^{\prime \prime}, U_{N}=49^{\circ} 34^{\prime} 15.7881^{\prime \prime}$ and between the meridians with the geographic longitudes $V_{W}=16^{\circ} 50^{\prime} 32.3600^{\prime \prime}$ and $V_{E}=22^{\circ} 34^{\prime} 50.6852^{\prime \prime}$. For a symmetric area, the coefficients $b$ are equal to zero, and equation (16) can be simplified:

$$
\ln v=\sum_{j=0}^{n} a_{j} \psi_{j}
$$

After minimizing the condition (12), where the scale distortion factor is calculated by:

$$
\ln m=\sum_{j=0}^{n} a_{j} \psi_{j}-\ln \cos U,
$$

and if $n=4$, we get a system of five equations in five variables, and the coefficients of the projection are the following:

$$
\begin{aligned}
& a_{0}=+0.247416, \\
& a_{1}=-0.530005, \\
& a_{2}=-0.269756, \\
& a_{3}=+0.156657, \\
& a_{4}=-0.038102 .
\end{aligned}
$$

If the natural logarithm of the scale distortion of the boundary points is equal to zero, the extremal values of the projection's scale distortion will be in the middle of the projected area. This can be reduced by the scale factor $m_{s}=2 /\left(m_{\max }+m_{\min }\right)$. The extremal scale distortion of the projection is from $-7.4 \mathrm{~cm} / \mathrm{km}$ to $+7.4 \mathrm{~cm} / \mathrm{km}$ (Fig. 2).

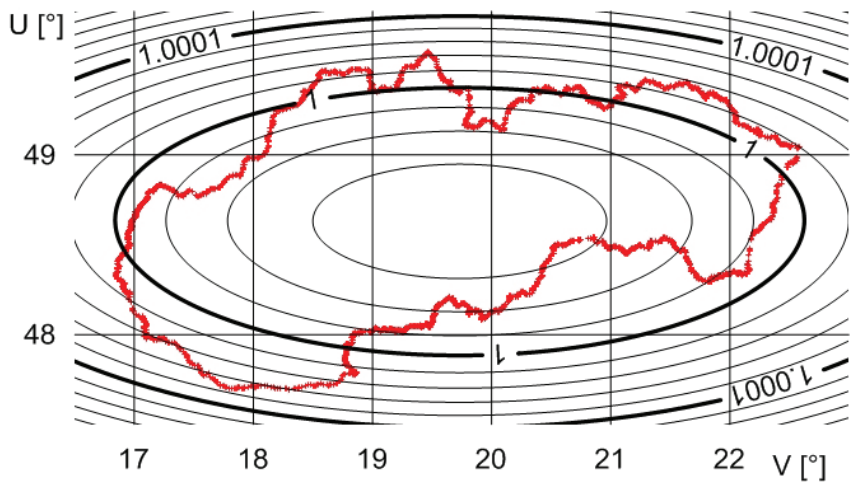

Fig. 2 Curves of the constant scale distortion - minimax projection for the geographic trapezium - the contour interval is $2 \mathbf{c m} / \mathbf{k m}$. 


\subsection{Minimax projection in an oblique position (cartographic trapezium)}

The second minimax projection is proposed for the cartographic trapezium in an oblique position using the cartographic pole $U_{K}=-5^{\circ} 53^{\prime} 41.1964^{\prime \prime}$ and $V_{K}=32^{\circ} 08^{\prime} 18.5219^{\prime \prime}$ (Vajsáblová and Szatmári, 2014). The advantage of this proposal is the smaller area of the trapezium; the disadvantage is the need for an additional transformation step (the spherical geographic coordinates $U, V$ to the spherical cartographic coordinates $S, D$ ). The Slovak Republic is situated on the sphere between parallels with the cartographic latitudes $S_{s}=35^{\circ} 05^{\prime} 05.7509^{\prime \prime}$, $S_{N}=33^{\circ} 23^{\prime} 42.1307^{\prime \prime}$ and between the meridians with the cartographic longitudes $D_{W}=12^{\circ} 13^{\prime} 59.6088^{\prime \prime}, D_{E}=7^{\circ} 34^{\prime} 55.6498^{\prime \prime}$. After minimizing the condition (12), where the following substitution was used:

$$
U=S, \quad V=D,
$$

we get a system of five equations in five variables, and the coefficients of the projection are the following:

$$
\begin{aligned}
& a_{0}=+4.708732, \\
& a_{1}=-29.101036, \\
& a_{2}=+67.246552, \\
& a_{3}=-70.412201, \\
& a_{4}=+27.642609 .
\end{aligned}
$$

The extremal scale distortion of the projection is from $-5.0 \mathrm{~cm} /$ $\mathrm{km}$ to $+5.0 \mathrm{~cm} / \mathrm{km}$ (Fig. 3).

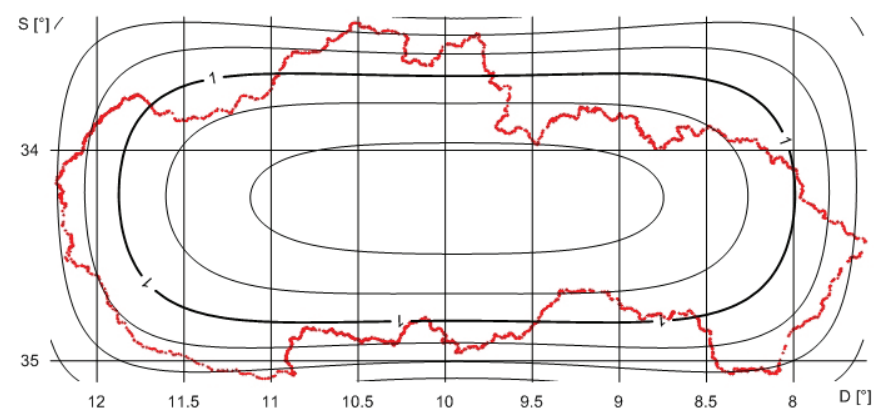

Fig. 3 Curves of the constant scale distortion - minimax projection for the cartographic trapezium - the contour interval is $2 \mathbf{c m} / \mathbf{k m}$.

\subsection{Minimax projection for an asymmetric area}

The third minimax projection is proposed for the country's actual boundary points. The important difference is that the coefficients $b_{1} \ldots$ $b_{4}$ are not equal to zero for an asymmetric area. After minimizing the condition (12), where the scale distortion factor is calculated by:

$$
\ln m=\sum_{j=0}^{n}\left(a_{j} \psi_{j}+b_{j} \tau_{j}\right)-\ln \cos U
$$

we get a system of nine equations in nine variables, and the coefficients of the projection are the following:

$$
\begin{aligned}
& a_{0}=+0.345199, \\
& a_{1}=-0.730073, \\
& a_{2}=-0.262013, \\
& a_{3}=+0.351807, \\
& a_{4}=-0.138660,
\end{aligned}
$$

$$
\begin{aligned}
& b_{0}=0, \\
& b_{1}=+0.526315, \\
& b_{2}=-0.032182, \\
& b_{3}=-0.488102, \\
& b_{4}=+0.250651 .
\end{aligned}
$$

The extremal scale distortion of the projection is from $-4.9 \mathrm{~cm} /$ $\mathrm{km}$ to $+4.9 \mathrm{~cm} / \mathrm{km}$ (Fig. 4 ).

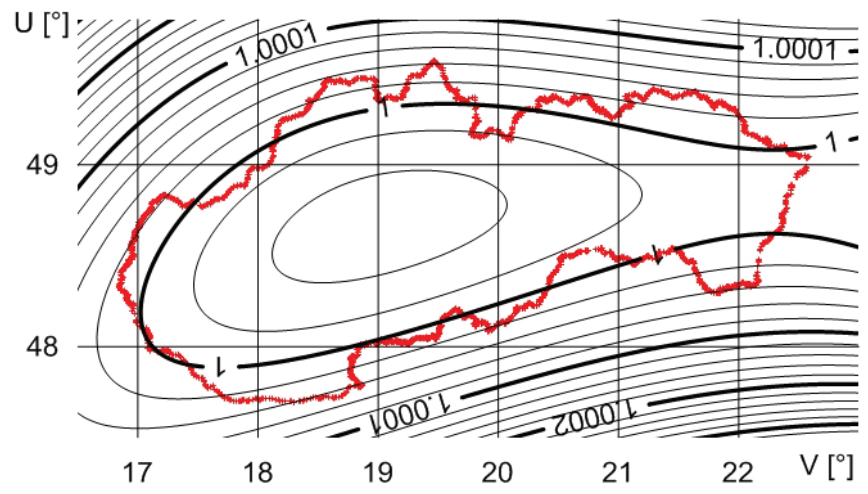

Fig. 4 Curves of the constant scale distortion - minimax projection for an asymmetric area defined by the actual boundary - the contour interval is $2 \mathbf{c m} / \mathbf{k m}$

\section{RESULTS}

The proposed cartographic projections were compared with the mentioned currently used projection defined by the law (Křovák's projection) and also with the new proposal, Lambert's projection by Vajsáblová. The extremal scale distortions are compared in Tab. 1. The valuation of the scale distortions were calculated by the additive criterion (11) for the $N=5424$ points and by the integral criterion by equation (10), where region $\Delta$ is limited by the boundaries of the Slovak Republic (Tab. 2).

Tab. 1 Extremal scale distortions of the cartographic projections. cartographic projection

scale distortion

$$
[\mathrm{cm} / \mathrm{km}]
$$

Křovák's projection

from -10.0 to +11.0

Lambert's projection

from -6.7 to +6.7

minimax projection for the geographical trapezium

minimax projection for the cartographical trapezium

minimax projection for asymmetric area

from -7.4 to +7.4

from -5.0 to +5.0

from -4.9 to +4.9

\section{CONCLUSIONS}

The comparison showed the disadvantages of the currently used map projection for the Slovak Republic and confirms the reliability of Lambert's projection with the parameters for the Slovak Republic within the group of cartographic projections on developable surfaces (cylindrical, conic and azimuthal projections). The main advantages of this projection are the normal position and the transformation of a 
Tab. 2 Square roots of the mean quadratic scale distortions of the cartographic projections.

\begin{tabular}{lcc}
\hline \multicolumn{1}{c}{ cartographic projection } & additive criterion & $\begin{array}{c}\text { integral criterion } \\
{[\mathrm{cm} / \mathrm{km}]}\end{array}$ \\
\hline Křovák's projection & {$[\mathrm{cm} / \mathrm{km}]$} & 6.96 \\
Lambert's projection & 7.15 & 5.12 \\
minimax projection for the geographical trapezium & 5.05 & 4.08 \\
minimax projection for the cartographical trapezium & 4.38 & 3.04 \\
minimax projection for asymmetric area & 2.99 & 2.38 \\
\hline
\end{tabular}

reference ellipsoid directly on a secant cone. The maximal scale distortion of this projection is $4.3 \mathrm{~cm} / \mathrm{km}$ smaller than the maximal scale distortion of Křovák's projection.

If we compare all of the above-proposed projections, the most suitable map projection is the above-described minimax projection for an asymmetric area defined by the country's actual boundary points.
The extremal scale distortion of the projection is from $-4.9 \mathrm{~cm} / \mathrm{km}$ to $+4.9 \mathrm{~cm} / \mathrm{km}$, which is smaller than the maximal scale distortion of Lambert's projection and Křovák's projection. The disadvantages of these minimax projections are the lack of geometric interpretation and the more difficult transformation of the coordinates. 


\section{REFERENCES}

Airy, G. B. (1861) Explanation of a projection by balance of errors for maps applying to a very large extent of the Earth's surface and comparison with other projections. Philosophical Magazine and Journal of Science. Vol. 22, pp. 409-421.

Chebyshev, P. L. (1962) Sur la construction des cartes géographiques. Oeuvres de P.L. Chebyshev. Chelsea.

Frankich, K. (1982) Optimization of geographic map projections for Canadian territory, Simon Fraser University, Canada.

Hojovec, V. - Šmehil, J. (1968) Kritéria pro posouzení vhodnosti kartografického zobrazeni z hlediska deformaci (Criterion for the valuation of cartographic projections in terms of distortion). Geodetický a kartografický obzor, Vol. 14(56), No. 1, pp. 9-12 [in Czech].

Hojovec, V. - Bořík, M. - Mikuta, V. - Mináŕ, P. (1997) Výsledky optimalizace konformního kartografického zobrazení pro Českou republiku (Results of the optimization of conformal cartographic projection for the Czech Republic). Geodetický a kartografický obzor, Vol. 43(85), No. 12, pp. 253-256 [in Czech].

Kavraiskii, V. V. (1959) Collected works 2. Moscow.
Skořepa, Z. - Dušek, R. (1997) Řešeni konformniho zobrazeni České republiky pomoci programu MATLAB (Design of a conformal projection of the Czech Republic using MATLAB). Geodetický a kartografický obzor, Vol. 43 (85), No. 6, pp. 119-124 [in Czech].

Srnka, E. (1986) Mathematical cartography. VAAZ, Brno [in Czech].

Urmaev, N. A. (1947) Methods for finding new cartographic projections. Moscow.

Vajsáblová, M. (2011) Návrh nového kartografického zobrazenia územia Slovenskej republiky (Proposal of the new cartographic projection of the Slovak Republic territory). Geodetický a kartografický obzor, Vol. 57(99), No. 8, pp. 185-190 [in Slovak].

Vajsáblová, M. (2014) Aspekty tvorby kartografického zobrazenia pre územie Slovenska (Aspects of the design of a cartographic projection for the territory of Slovakia). Habilitation thesis. Bratislava: SvF STU [in Slovak].

Vajsáblová, M. - Szatmári, D. (2014) Variational cartographic projections for the Slovak Republic territory. Scientific Research and Essays, Vol. 9, No. 6, pp. 114-120. 